\title{
Impact of one-week preoperative physical training on clinical outcomes of surgical lung cancer patients with limited lung function: a randomized trial
}

\author{
Yutian Lai ${ }^{1 \#}$, Xin Wang ${ }^{1,2 \#}$, Kun Zhou ${ }^{1}$, Jianhuan $\mathrm{Su}^{3}$, Guowei Che ${ }^{1}$ \\ ${ }^{1}$ Department of Thoracic Surgery, West China Hospital, Sichuan University, Chengdu 610041, China; ${ }^{2}$ Department of Thoracic Surgery, Cancer \\ Hospital \& Institute, Sichuan Cancer Center, School of Medicine, University of Electronic Science and Technology of China, Chengdu 610000, \\ China; ${ }^{3}$ Rehabilitation Department, West China Hospital, Sichuan University, Chengdu 610041, China \\ Contributions: (I) Conception and design: G Che, Y Lai; (II) Administrative support: G Che, Y Lai; (III) Provision of study materials or patients: J \\ Su; (IV) Collection and assembly of data: X Wang, Y Lai, K Zhou; (V) Data analysis and interpretation: K Zhou, J Su; (VI) Manuscript writing: All \\ authors; (VII) Final approval of manuscript: All authors. \\ \#These authors contributed equally to this work. \\ Correspondence to: Guowei Che, PhD, MD. Department of Thoracic Surgery, West China Hospital, Sichuan University, Chengdu 610041, China. \\ Email: cheguowei_hx@aliyun.com.
}

Background: To investigate the influence of preoperative physical training combining aerobic and breathing exercises on surgical lung cancer patients with impaired lung function.

Methods: A total of 68 patients with predicted postoperative FEV1\% $<60 \%$ were equally and randomly assigned into one-week physical training combining aerobic and breathing exercises (intervened group: IG) or routine preoperative preparation (control group: CG). Then, 6-min walking distance (6-MWD), inhospital length of stay (LOS), and other clinical variables were included and recorded.

Results: An increase of $22.6 \pm 27.0 \mathrm{~m}$ of $6-\mathrm{MWD}$ was observed in $\mathrm{IG}$, compared to $2.7 \pm 27.6 \mathrm{~m}$ in $\mathrm{CG}$ (between-group difference: $19.9 \mathrm{~m}, 95 \% \mathrm{CI}$ : 6.7 to 33.2, $\mathrm{P}=0.004$ ), but no difference was found in lung function. The emotional function of EORTC-QLQ-30 was significantly improved in IG after the training regimen, compared to CG. Meanwhile, the intervened patients (IG) had significantly lower postoperative pulmonary complication (PPC) rate $(11.8 \%$, $4 / 34$ vs. 35.3\%, 12/34, $\mathrm{P}=0.022)$, shorter postoperative LOS [median: 5.0 interquartile (4.0-7.0) vs. 8.0 (7.0-10.0) days, $\mathrm{P}<0.001$ ] and lower costs, including total cost $[48,588.7(44,999.1-52,693.3)$ vs. 52,445.3 (49,002.9-61,994.0) $¥, \mathrm{P}=0.016]$, material cost $[23,350.8$ $(18,300.6-26,421.9)$ vs. 25,730.0 (21,328.7-29,250.2) $¥, \mathrm{P}=0.048]$ and drug cost $[7,230.0(6,661.9-8,347.4)$ vs. $11,388.6(7,963.0-16,314.3) ¥, \mathrm{P}<0.001]$.

Conclusions: The preoperative physical training combining aerobic and breathing exercises can improve exercise capacity, decrease the occurrence of PPCs, and shorten LOS with lower in-hospital cost; it thus shows potential to be an effective preparation strategy for surgical lung cancer patients with limited lung function.

Keywords: Exercise; thoracic surgery; lung cancer; 6-min walk distance; lobectomy; lung function

Submitted Jun 20, 2019. Accepted for publication Sep 10, 2019.

doi: 10.21037/atm.2019.09.151

View this article at: http://dx.doi.org/10.21037/atm.2019.09.151 


\section{Introduction}

As the most common and deadly malignancy worldwide, lung cancer threatens health and incurs a heavy financial on society and families. Surgery is the curative option for this pathology and is considered as the optimal strategy for patients with early or resectable tumors $(1,2)$. Due to reduced lung function and sequential postoperative pulmonary complications (PPCs), lung cancer patients often need extended hospitalization and endure greater costs after surgery (3). For lung cancer patients waiting for surgery, effective comprehensive clinical preparation including physical training may potentially decrease the risk of PPCs and considerably improve outcomes (4-6). Chinese Consensus Statement on Perioperative Airway Management by Multi-disciplinary Team (Pannel 2016) (7) has recommended perioperative comprehensive pulmonary rehabilitation including physical exercise for patients, as it potentially helps to strengthen cardiopulmonary intolerance and thereby decrease the incidence of PPCs.

Clinical experiments show the effectiveness and feasibility of physical training as a cost-effective intervention strategy for preoperative conditioning, especially for patients at a high risk of PPC due to low lung functions (8-10). However, there is limited evidence for the feasibility and practicability of physical training, and only a few studies have confirmed that certain training programs, including breathing exercise and aerobic exercise, can shorten the hospitalization time and reduce the PPC rate in lung cancer patients. Also, the impact of oneweek preoperative physical training on clinical outcomes, including exercise capacity of surgical lung cancer patients with limited lung function, is still unclear. For this reason, the research team of our hospital aimed to examine the effectiveness of preoperative physical training combining aerobic and breathing exercises in cardiopulmonary function or postoperative outcomes for lung cancer patients with ppoFEV1\% (predicted postoperative forced expiratory volume in one second) $<60 \%$. We hope to provide tangible evidence concerning the positive effect of physical exercise on this population.

\section{Methods}

\section{Ethical review}

Ethical approval was obtained from the Clinical Trials and Biomedical Ethics Committee of our hospital (No. 2018134), and the registration number was ChiCTR1800014512
(Chinese Clinical Trial registry). We strictly followed the Declaration of Helsinki and obtained written informed consent from all the participants.

\section{Blinding and grouping}

The patients were randomly assigned into one of two treatment types using a random number table after baseline assessments were completed. Due to the nature of this research, we could not keep the participants blind to group assignment, but the study staff and statistical analyses were all blind to patient allocation during data collection.

\section{Patients}

Patients enrolled needed to meet all the following criteria: (I) diagnosis of non-small cell lung cancer (NSCLC) in the thoracic department of our hospital, a regional tertiary center; (II) reception of video-assisted thoracic surgery (VATS) lung cancer lobectomy with ppoFEV1\% < $60 \%$; (III) and age between 45 to 80 years old; (IV) agreement to participate in the study with a consent. The exclusion criteria included any contraindication to exercise or risk of adverse events, such as unsteady chest pain, uncontrolled high blood pressure or irregular heartbeat, serious aortic stenosis, acute illness or fever, severe arrhythmia, and musculoskeletal or mental disorders

\section{Assessment}

\section{The six-minute walk test (6-MWT)}

The 6-MWT was performed following the American Thoracic Society (ATS) Pulmonary Function Standards Committee recommendations (11). The test was conducted on a 40-m hallway with flat hard surfaces marked with alternating-colored tiles; a finger-probe pulse oximeter was used to obtain oxygen saturation and heart rate before and at the end of the 6-MWT, and the Borg dyspnea score, fatigue index, and peak expiratory flow (PEF) were also recorded. A physician was available during each test to resuscitate a patient, if necessary.

\section{QOL}

QOL was evaluated using EORTC-QLQ-C30, a diseasespecific health-related QOL scale ranging from 0 to 100 , wherein a higher score reflects either better function or worse symptomatic effect $(12,13)$. 


\section{Pulmonary function test}

The pulmonary function test included forced vital capacity (FVC) and FEV 1, MVV, and DLco. The postoperative predicted FEV1\% (ppoFEV1\%) or postoperative predicted DLCO \% (ppoDLCO\%) were calculated using the anatomic method with the following equation: ppoFEV $1 \%$ $($ or $\mathrm{ppoDLCO} \%)=$ measured $\mathrm{FEV} 1 \%($ or $\mathrm{DLCO} \%) \times(19$ - $\mathrm{n}$ of segments resected)/19.

\section{Intervention process}

All participants received assessments upon admission, including pulmonary function test, 6-MWT, and QOL, while arterial blood gas (ABG) was sampled on the first day in the resting position.

Patients in the intervention group (IG) received oneweek physical training of which included the following: (I) breathing exercise, 20 breaths/session for 3 sessions/day via a volumetric Incentive spirometer (HUDSON RCI 2500, TeleflexInc, USA) under the guidance of specialized nurses; (II) aerobic exercise, $30 \mathrm{~min} /$ session every day via a $\mathrm{Nu}-\mathrm{Step}$ instrument (NuStep Inc. Michigan) under the supervision of physical therapists. The spirometer was a visual feedback device that encourages maximal inspiration, including breath-holding. In contrast, patients in the control group (CG) received routine preparation, including laboratory and radiological examinations and preoperative education. All the tests or examinations, including the pulmonary function test, 6-MWT, QOL assessment, and blood-gas analysis, were conducted one week later.

\section{Study endpoints}

\section{Primary endpoint}

The primary endpoint was the change in 6-MWD conducted on the first day and one week later to evaluate the exercise capacity of patients.

\section{Secondary endpoints}

Lung function including FEV1, FVC, DLCO, and PPCs was investigated. The criteria for PPCs was based on the STS/ ESTS complication definition (14). Pneumonia was defined as per the last Centers for Disease Control criteria: new or progressive and persistent infiltration and consolidation or cavitation found on chest radiographs. Also, at least one of the following needed to be met: fever $\left(>38^{\circ} \mathrm{C}\right)$ without other clarified causes; leukopenia $\left(<4,000 \mathrm{WBC} / \mathrm{mm}^{3}\right)$ or leukocytosis $\left(>12,000 \mathrm{WBC} / \mathrm{mm}^{3}\right)$; for patients $>70$ years old, change in mental status with purulent sputum or change in character, and respiratory secretions increasing or needing suction; onset or worsening symptoms (e.g., dyspnea, tachypnea) or clinical signs (e.g., rales, bronchial breath sounds). Meanwhile, according to the rule of Clavien-Dindo complication classification (15), PPCs were classified and divided into 5 grades, which are detailed in supporting Table 1 .

Additional data collected during the 6-MWT included an index of fatigue and dyspnea during exercise. Blood gas analysis including blood oxygen saturation, partial pressures of oxygen (PO2), and carbon dioxide (PCO2) were also compared before and after the one-week regimen.

\section{Statistical analysis}

Our earlier study reported the change in 6-MWD before and after the one-week period in the IG and CG groups $(22.9 \pm 25.9 v s .4 .2 \pm 24.2 \mathrm{~m})(10)$. Under the assumption of normal distribution and with a power of $80 \%$ and alpha of 0.05 , the estimated minimal sample size was 34 for each group. Finally, 70 patients were included in the study with 34 in each group. The sample sizes were calculated on PASS 11.0.7 for Windows.

Continuous variables were expressed as mean and standard deviations (SD). Data not obeying normal distribution were presented as median and range, and binary variables were presented as proportions. Data were compared via Fisher's exact test, Chi-square test, or Student's $t$-test as appropriate. Significant level was $\mathrm{P}<0.05$. Statistical analyses were carried out on SPSS 21.0.

\section{Results}

\section{Baseline characteristics}

Initially, 132 patients were screened, 42 of whom failed to meet the inclusion criteria, and 22 of whom declined to take part. These patients were excluded. Finally, 68 patients were enrolled. Concerning the patients enrolled and randomly assigned, 2 IG patients did not complete the training program, as they could not endure the training intensity (one stopped after the third training day and one at the fourth). Two IG patients and 3 controls were non-NSCLC, and were all inflammatory nodules except for 1 small cell lung cancer patient in the CG group. However, according to the intention of the treatment principle, all the randomized patients were included in the analysis. The study flow can be seen in supporting Figure 1 . 
Table 1 Classifications of postoperative pulmonary complications of thoracic surgery

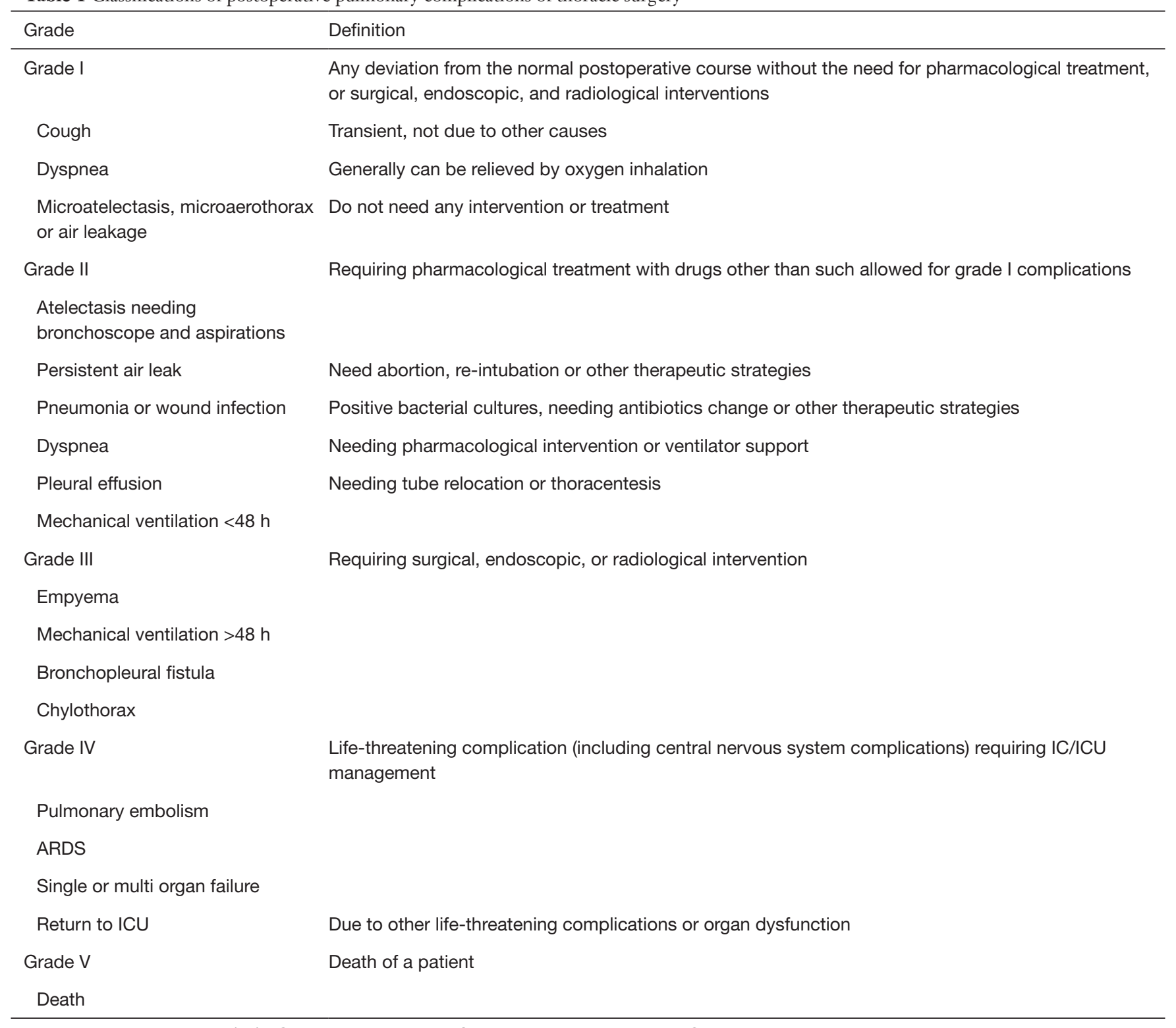

According to Dindo et al. (15). IC, intermediate care; ICU, intensive care unit; ARDS, adult respiratory distress syndrome.

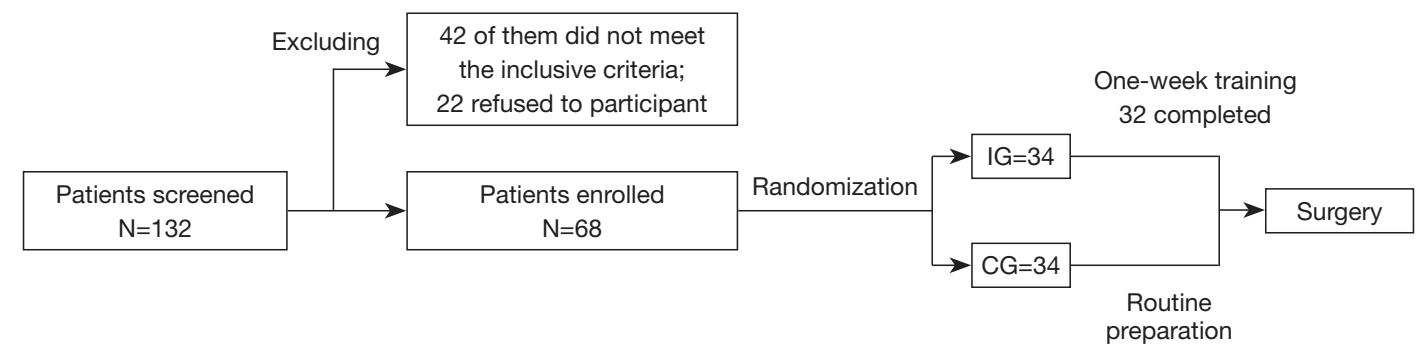

Figure 1 Study flow. 
The baseline characteristics were comparable between the groups (Table 2).

\section{Before and after the training program}

Concerning 6-MWD, an increase of $22.6 \pm 27.0 \mathrm{~m}$ was observed in IG, compared to $2.7 \pm 27.6 \mathrm{~m}$ in CG (betweengroup difference: $19.9 \mathrm{~m}, 95 \% \mathrm{CI}: 6.7$ to $33.2, \mathrm{P}=0.004$ ). No significant difference between groups was found in lung function including FEV1, FVC, DLco, PEF, index of fatigue, index of dyspnea during 6-MWT, blood gas analysis, or EORTC QLQ-C30 scores except for emotional function $(\mathrm{Z}=3.363, \mathrm{P}=0.001)$ (Table 3).

\section{Length of stay (LOS) and in-bospital cost}

The IG group compared to the CG group had shorter postoperative in-hospital LOS [5.0 (4.0-7.0) vs. 8.0 (7.0-10.0) days, $\mathrm{P}<0.001]$ and lower costs, including total cost $[48,588.7(44,999.1-52,693.3$ vs. 52,445.3 (49,002.9$61,994.0) ¥, \mathrm{P}=0.016]$, material cost $[23,350.8(18,300.6-$ $26,421.9)$ vs. $25,730.0(21,328.7-29,250.2) ¥, \mathrm{P}=0.048]$ and drug cost $[7,230.0(6,661.9-8,347.4)$ vs. 11,388.6 (7,963.0$16,314.3) ¥, \mathrm{P}<0.001]$ (Table 2).

\section{PPCs}

According to the Clavien-Dindo complication classification, the PPCs were stratified into five grades, and categories of PPCs are listed in Table 4. Lower PPC rate (defined as PPCs of grade II to V) was found in IG $(11.8 \%, 4 / 34 v s$. $35.3 \%, 12 / 34, \mathrm{P}=0.022)$ (Table 5).

\section{Discussion}

Lung cancer still ranks first among all cancers in terms of incidence and death rates worldwide, including in China. Surgery is deemed as the optimal strategy or option for patients with early or resectable tumors. Due to reduced lung function and sequential PPCs, lung cancer patients often need extended hospitalization and endure higher costs after surgeries. Recently, an emerging enhanced recovery after surgery (ERAS) program that is effective in decreasing postoperative morbidity and mortality has received growing attention (16). As an essential part of the ERAS program, preoperative training can optimize the fitness and health status for patients undergoing thoracic surgery. Patients with pulmonary function impairment are at an elevated risk of perioperative complications (17), and the risk of surgery is widely assessed by the postoperative predictive (ppo) values of FEV1, an independent predictor of occurrence and complications after lung resection. Our previous study conducted in 2017 randomly included 101 patients. In this study, we selected patients with risk factors of PPCs, but because of the limited sample size, it was impossible to perform sub-group analysis to investigate which group of patients needed to receive physical training before surgery or which group could benefit most from this regimen. Hence, we conducted this study with a focus one those patients with ppoFEV $1 \%<60 \%$ to identify the influence of this regimen on the patients with limited lung function.

We selected ppoFEV $1 \%<60 \%$ as the inclusive criteria because FEV1 is a variable which is cost-effective to measure, is widely used to assess and screen the risk of the surgical the population, and is an evidence-supported independent risk factor for poor outcomes after surgery (18).

Ideally, exercise training initiatives should begin with a minimum period of four weeks to meaningfully improve fitness. However, this relatively "long" period seems to be unacceptable for those suspected lung cancer patients waiting for thoracic surgery and would lead to unsatisfactory low compliance. In China, the underdeveloped and regionally imbalanced condition of basic medical care or community health systems makes home-based training or exercise inapplicable to community institutions $(19,20)$. Therefore, high-intensity interval training (HIT) has been studied to strengthen aerobic abilities effectively (21). Traditionally, breath training is widely used to improve the inspiratory muscle endurance, exercise functions, and labored respiration of patients with COPD, wheezing, or lung dysfunction $(22,23)$. Meanwhile, endurance training (ET) is preferentially adopted in rehabilitation to increase blood volume, cardiac output, and muscle oxygen extraction and thereby enhance exercise resistance and aerobic capabilities (24). In this study, a one-week HIT combining both inspiratory training and endurance exercise was conducted to enhance the fitness, health status, and subsequent postoperative outcomes.

In the study, all but 2 patients could endure the training intensity, which attests to the feasibility and safety of this training mode.

The main findings in previous studies concerning physical training include the enhancement of cardiorespiratory functions. Our earlier study in 2017 involving patients with several risk factors of PPCs demonstrated that this training regimen could improve 
Table 2 baseline characteristics between the two groups

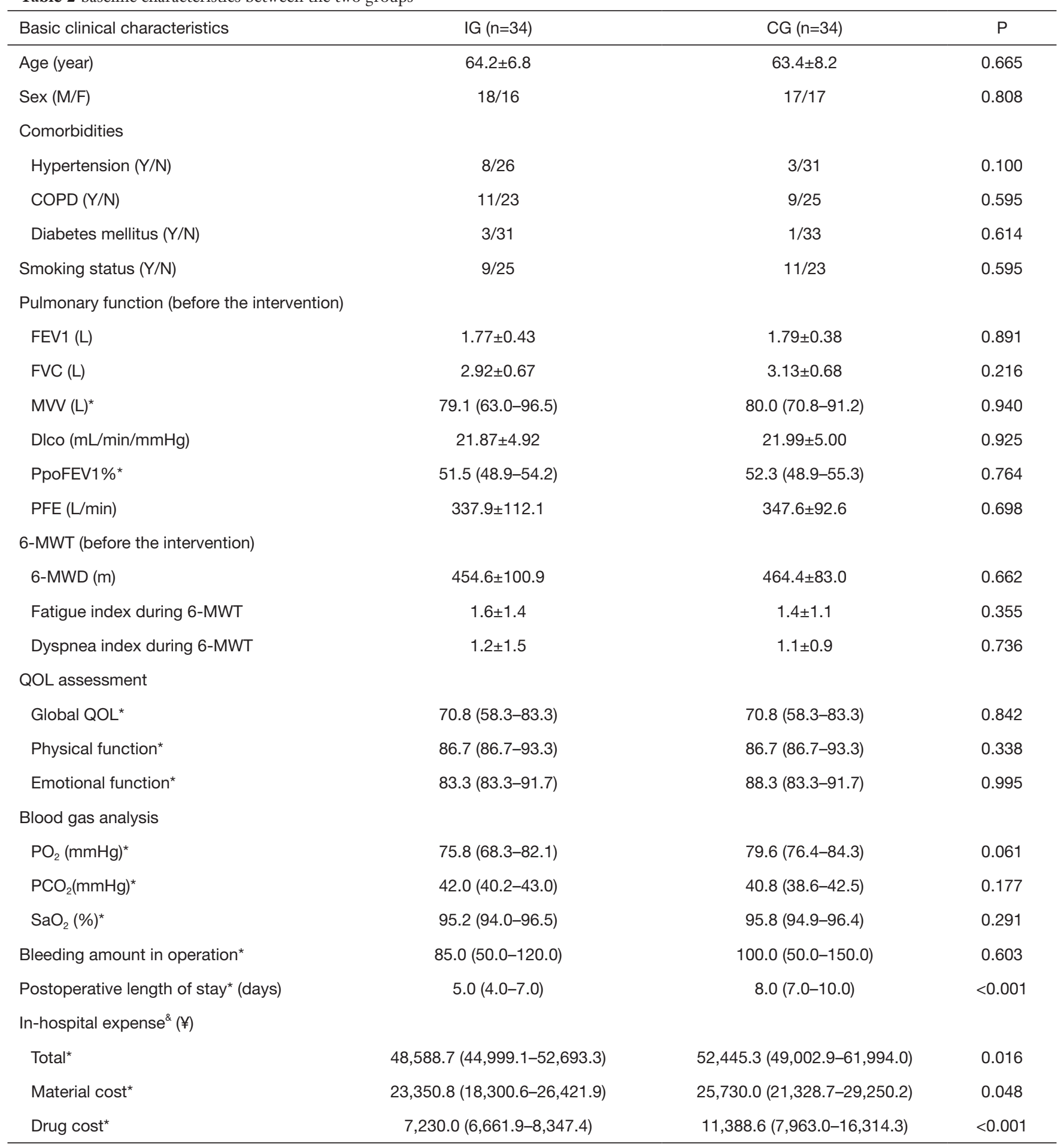

${ }^{*}$, non-normal distribution variables described as median (interquartile); ${ }^{\&}$, in-hospital expense included the costs during the in-hospital stay. Total expense included all the in-hospitalization costs, material or drug cost include expense for all the material or drug use during in-hospitalization. IG, intervention group; CG, control group; COPD, chronic obstructive pulmonary disease defined as FEV1/FVC $<70 \%$ and FEV1 $<80 \%$ of predicted; FEV1, forced expiratory volume in one second; FVC, forced vital capacity; Dlco, diffusion capacity for carbon monoxide of the lung; ppoFEV1\%, postoperative predicted FEV1\%; MVV, maximal voluntary ventilation; PEF, peak expiratory flow; 6-MWD, 6-min walk distance; $\mathrm{PO}_{2}$, partial pressure of oxygen; $\mathrm{PCO}_{2}$, partial pressure of carbon dioxide; $\mathrm{SaO}_{2}$, arterial oxygen saturation; $\mathrm{QOL}$, quality of life. 
Table 3 Between-group difference before and after the intervention in the two groups

\begin{tabular}{|c|c|c|}
\hline Variables & $\begin{array}{c}\text { Between-group } \\
\text { difference* or Z value }{ }^{\&}\end{array}$ & $P$ \\
\hline FEV1 (L)* & $0.002(-0.03$ to 0.02$)$ & 0.888 \\
\hline $\mathrm{FVC}(\mathrm{L})^{*}$ & 0.01 ( -0.03 to 0.06$)$ & 0.562 \\
\hline Dlco $(\mathrm{mL} / \mathrm{min} / \mathrm{mmHg})^{\star}$ & $-0.3(-1.0$ to 0.4$)$ & 0.337 \\
\hline PFE (L/min)* & $10.1(-7.2$ to 27.5$)$ & 0.250 \\
\hline 6-MWD $(\mathrm{m})^{\star}$ & 19.9 (6.7 to 33.2$)$ & 0.004 \\
\hline Index of fatigue after 6-MWT ${ }^{\&}$ & 0.686 & 0.493 \\
\hline Index of dyspnea after 6-MWT ${ }^{\&}$ & 1.179 & 0.239 \\
\hline \multicolumn{3}{|l|}{ QOL evaluation } \\
\hline Global QOL ${ }^{\&}$ & 0.409 & 0.683 \\
\hline Physical function ${ }^{\&}$ & 1.447 & 0.148 \\
\hline Emotional function ${ }^{\&}$ & 3.363 & 0.001 \\
\hline \multicolumn{3}{|l|}{ Blood gas analysis } \\
\hline $\mathrm{PO}_{2}(\mathrm{mmHg})^{\&}$ & 1.896 & 0.058 \\
\hline $\mathrm{PCO}_{2}(\mathrm{mmHg})^{\&}$ & 1.632 & 0.106 \\
\hline $\mathrm{SaO}_{2}(\%)^{\&}$ & 1.928 & 0.054 \\
\hline
\end{tabular}

*, for normal distribution variables, between-group difference was presented as mean difference $(95 \% \mathrm{Cl}) .{ }^{\&}$, for non-normal distribution variables, $Z$ value of Mann-Whitney test was listed in the column. $\mathrm{Cl}$, confidence interval; PEF, peak expiratory flow; 6-MWD, 6-min walk distance; 6-MWT, 6-min walk test; $\mathrm{PO}_{2}$, partial pressure of oxygen; $\mathrm{PCO}_{2}$, partial pressure of carbon dioxide; $\mathrm{SaO}_{2}$, arterial oxygen saturation; QOL, quality of life; FEV1, forced expiratory volume in one second; FVC, forced vital capacity; Dlco, diffusion capacity for carbon monoxide of the lung.

cardiopulmonary endurance or exercise capacity (10). The $\Delta 6$-MWD (difference of 6-MWT scores before and after the program) of the IG group was significantly higher than that in the CG group, indicating this shortterm high-intensity training regimen could improve cardiopulmonary endurance. However, concerning lung function, unfortunately we found no difference between the two groups before and after this one-week period, which may due to inadequacy of the intensity or duration of this training regimen to improve lung function or the relatively small sample size. Meanwhile, regarding health-related QOL, no difference was observed except for emotional function, suggesting the intense training before surgery is only effective on mental health. Potential reasons may
Table 4 categories of PPCs between groups

\begin{tabular}{|c|c|c|c|}
\hline Complication & IG $(n=34)$ & $C G(n=34)$ & $P$ value \\
\hline \multicolumn{4}{|l|}{ Grade I, n (\%) } \\
\hline Dyspnea & $8(23.5)$ & $9(26.5)$ & 0.779 \\
\hline Cough & $6(17.6)$ & $9(26.5)$ & 0.380 \\
\hline $\begin{array}{l}\text { Microatelectasis, } \\
\text { microaerothorax or air leakage }\end{array}$ & $6(17.6)$ & $6(17.6)$ & 1.000 \\
\hline \multicolumn{4}{|l|}{ Grade II, n (\%) } \\
\hline Pneumonia or wound infection & $3(8.8)$ & $6(17.6)$ & 0.476 \\
\hline Mechanical ventilation $<48 \mathrm{~h}$ & $0(0.0)$ & $3(8.8)$ & 0.239 \\
\hline $\begin{array}{l}\text { Pleural effusion needing tube } \\
\text { relocation or thoracentesis }\end{array}$ & $2(5.9)$ & $2(5.9)$ & 1.000 \\
\hline $\begin{array}{l}\text { Atelectasis needing } \\
\text { bronchoscope and aspirations }\end{array}$ & $1(2.9)$ & $3(8.8)$ & 0.614 \\
\hline $\begin{array}{l}\text { Dyspnea pharmacological } \\
\text { intervention or ventilator support }\end{array}$ & $2(5.9)$ & $4(11.8)$ & 0.673 \\
\hline Air leak & $3(8.8)$ & $4(11.8)$ & 1.000 \\
\hline \multicolumn{4}{|l|}{ Grade III, n (\%) } \\
\hline Empyema & $0(0.0)$ & $1(2.9)$ & 1.000 \\
\hline Mechanical ventilation $>48 \mathrm{~h}$ & $0(0.0)$ & $1(2.9)$ & 1.000 \\
\hline Bronchopleural fistula & $0(0.0)$ & $0(0.0)$ & 1.000 \\
\hline Chylothorax & $0(0.0)$ & $1(2.9)$ & 1.000 \\
\hline \multicolumn{4}{|l|}{ Grade IV, n (\%) } \\
\hline Return to ICU & $0(0.0)$ & $1(2.9)$ & 1.000 \\
\hline Pulmonary embolism & $0(0.0)$ & $0(0.0)$ & 1.000 \\
\hline ARDS & $0(0.0)$ & $0(0.0)$ & 1.000 \\
\hline Single or multi organ failure & $0(0.0)$ & $0(0.0)$ & 1.000 \\
\hline \multicolumn{4}{|l|}{ Grade V, n (\%) } \\
\hline Death & $0(0.0)$ & $0(0.0)$ & 1.000 \\
\hline
\end{tabular}

PPC, postoperative pulmonary complication; IG, intervention group; CG, control group.

be that firstly, the exercise training helped them relax and relieve anxiety, and secondly, the communications and supervision of the specialized nurses or physical therapists relieved stress to some extent. Though we had no relevant data or evidence to validate whether the improvement of mental status was beneficial for postoperative recovery, this improvement was undoubtedly beneficial for patients.

PPCs are considered the critical factor that negatively influences recovery outcomes, leading to elevated risk of 
Table 5 PPC rate in Clavien-Dindo classification (I-V) between two groups

\begin{tabular}{lccc}
\hline Complication grade & IG, n (\%) & CG, n (\%) & P \\
\hline Grade I & $14(41.2)$ & $20(58.8)$ & 0.146 \\
Grade II & $4(11.8)$ & $10(29.4)$ & 0.072 \\
Grade III & $0(0.0)$ & $3(8.8)$ & 0.239 \\
Grade IV & $0(0.0)$ & $1(2.9)$ & 1.000 \\
Grade V & $0(0.0)$ & $0(0.0)$ & 1.000 \\
PPC rate* (Grade II to V) & $4(11.8)$ & $12(35.3)$ & 0.022 \\
\hline
\end{tabular}

*, PPC rate is defined as PPCs of Grade II to V. PPC, postoperative pulmonary complication; IG, intervention group; CG, control group.

mortality. Whether pre-rehabilitation can reduce PPCs in surgical lung cancer patients still is unclear. The results of studies examining this have been affected by such factors as the population, type of rehabilitation regimen, and the duration or definition of PPCs. In our study, lower PPCs rates were found in the IG group, which led to shorter LOS and better postoperative recovery. The reason for the decrease of the PPC rate in the intervention group might be that the rehabilitation regimen improved the inspiratory muscle endurance, exercise functions, and labored respiration of patients, while increasing blood volume, cardiac output, and muscle oxygen extraction. This may have thereby enhanced exercise resistance and aerobic capabilities, leading to better health status before surgery and better recovery after surgery. Another aspect of interest is postoperative LOS. A shorter postoperative LOS moderately indicates better recovery outcomes after surgery and less subsequent in-hospital expense. The proof that effective pre-rehabilitation contributes to shortening postoperative LOS is also confirmed in our study. Meanwhile, drug cost and total in-hospital expense decreased in the CG patients, showing this training regimen is cost-effective for surgical lung cancer patients with limited lung function.

This study also has some limitations. Firstly, the included participants came from a single medical center and received surgery from a small group of surgeons. Secondly, we selected the patients undergoing VATS lobectomy with ppoFEV $1 \%<60 \%$, but several non-NSCLC patients were also included for the intention-to-treatment principal, which might have been a confounding factor and inevitably resulted in other bias of lower generalization. Thirdly, cardiopulmonary capacity was evaluated only using 6-MWT, but other measurements, including cardiopulmonary exercise test, could be used in the future for more comprehensive assessment. Furthermore, the current study was conducted subsequent to our 2017 study, and no difference was found in lung function; thus, further study with a larger sample size is required. Last but not the least, we only roughly analyzed the drug cost, material cost and total cost in the study, and any further study should adopt a finer approach to investigate the cost-effectiveness of the rehabilitation regimen.

\section{Conclusions}

The one-week preoperative physical training combining aerobic and breathing exercises can improve cardiopulmonary tolerance, decrease the occurrence of PPCs, and shorten in-hospital LOS with lower in-hospital cost; thus, this is a potential preparation strategy for surgical lung cancer patients with reduced lung function.

\section{Acknowledgments}

None.

\section{Footnote}

Conflicts of Interest: The authors have no conflicts of interest to declare.

Ethical Statement: The authors are accountable for all aspects of the work in ensuring that questions related to the accuracy or integrity of any part of the work are appropriately investigated and resolved. Ethical approval was obtained from the Clinical Trials and Biomedical Ethics Committee of our hospital (No. 2018-134), and written informed was obtained consent from all the participants.

\section{References}

1. Sherwood JT, Brock MV. Lung cancer: new surgical approaches. Respirology 2007;12:326-32.

2. Pearse RM, Moreno RP, Bauer P, et al. Mortality after surgery in Europe: a 7 day cohort study. Lancet 2012;380:1059-65.

3. Lugg ST, Agostini PJ, Tikka T, et al. Long-term impact of developing a postoperative pulmonary complication after 
lung surgery. Thorax 2016;71:171-6.

4. Piraux E, Caty G, Reychler G. Effects of preoperative combined aerobic and resistance exercise training in cancer patients undergoing tumour resection surgery: A systematic review of randomised trials. Surg Oncol 2018;27:584-94.

5. Sanchez-Lorente D, Navarro-Ripoll R, Guzman R, et al. Prehabilitation in thoracic surgery. $\mathrm{J}$ Thorac Dis 2018;10:S2593-600.

6. Tew GA, Ayyash R, Durrand J, et al. Clinical guideline and recommendations on pre-operative exercise training in patients awaiting major non-cardiac surgery. Anaesthesia 2018;73:750-68.

7. Expert consensus on multi-disciplinary airway management (2016 edition). Chinese J Clin Thorac Cardiovasc Surg 2016;23:641-5.

8. Crandall K, Maguire R, Campbell A, et al. Exercise intervention for patients surgically treated for Non-Small Cell Lung Cancer (NSCLC): a systematic review. Surg Oncol 2014;23:17-30.

9. Fiore JF Jr, Bejjani J, Conrad K, et al. Systematic review of the influence of enhanced recovery pathways in elective lung resection. J Thorac Cardiovasc Surg 2016;151:708-15.e6.

10. Lai Y, Su J, Qiu P, et al. Systematic short-term pulmonary rehabilitation before lung cancer lobectomy: a randomized trial. Interact Cardiovasc Thorac Surg 2017;25:476-83.

11. Marjanski T, Badocha M, Wnuk D, et al. Result of the 6-min walk test is an independent prognostic factor of surgically treated non-small-cell lung cancer. Interact Cardiovasc Thorac Surg 2019;28:368-74.

12. Maringwa JT, Quinten C, King M, et al. Minimal important differences for interpreting health-related quality of life scores from the EORTC QLQ-C30 in lung cancer patients participating in randomized controlled trials. Support Care Cancer 2011;19:1753-60.

13. Giesinger JM, Kieffer JM, Fayers PM, et al. Replication and validation of higher order models demonstrated that a summary score for the EORTC QLQ-C30 is robust. J Clin Epidemiol 2016;69:79-88.

14. Seder CW, Salati M, Kozower BD, et al. Variation in

Cite this article as: Lai Y, Wang X, Zhou K, Su J, Che G. Impact of one-week preoperative physical training on clinical outcomes of surgical lung cancer patients with limited lung function: a randomized trial. Ann Transl Med 2019;7(20):544. doi: 10.21037/atm.2019.09.151
Pulmonary Resection Practices Between The Society of Thoracic Surgeons and the European Society of Thoracic Surgeons General Thoracic Surgery Databases. Ann Thorac Surg 2016;101:2077-84.

15. Dindo D, Demartines N, Clavien PA. Classification of surgical complications: a new proposal with evaluation in a cohort of 6336 patients and results of a survey. Ann Surg 2004;240:205-13.

16. Muehling BM, Halter GL, Schelzig H, et al. Reduction of postoperative pulmonary complications after lung surgery using a fast track clinical pathway. Eur J Cardiothorac Surg 2008;34:174-80.

17. Baser S, Shannon VR, Eapen GA, et al. Pulmonary dysfunction as a major cause of inoperability among patients with non-small-cell lung cancer. Clin Lung Cancer 2006;7:344-9.

18. Detterbeck FC, Mazzone PJ, Naidich DP, et al. Screening for lung cancer: Diagnosis and management of lung cancer, 3rd ed: American College of Chest Physicians evidence-based clinical practice guidelines. Chest 2013;143:e78S-92S.

19. Xu J, Wang W, Li Y, et al. Analysis of factors influencing the outpatient workload at Chinese health centres. BMC Health Serv Res 2010;10:151.

20. Shi L, Starfield B, Politzer R, et al. Primary care, selfrated health, and reductions in social disparities in health. Health Serv Res 2002;37:529-50.

21. Edvardsen E, Skjønsberg OH, Holme I, et al. Highintensity training following lung cancer surgery: a randomised controlled trial. Thorax 2015;70:244-50.

22. Gosselink R, De Vos J, van den Heuvel SP, et al. Impact of inspiratory muscle training in patients with COPD: what is the evidence? Eur Respir J 2011;37:416-25.

23. Weiner $P$, Weiner $M$. Inspiratory muscle training may increase peak inspiratory flow in chronic obstructive pulmonary disease. Respiration 2006;73:151-6.

24. Wall BT, Dirks ML, van Loon LJ. Skeletal muscle atrophy during short-term disuse: implications for age-related sarcopenia. Ageing Res Rev 2013;12:898-906. 